\begin{abstract}
Iterability, the repetition which alters the idealization it reproduces, is the engine of deconstructive movement. The fact that all experience is transformative-dissimulative in its essence does not, however, mean that the momentum of change is the same for all situations. Derrida adapts Husserl's distinction between a bound and a free ideality to draw up a contrast between mechanicalmathematical calculation, whose in-principle infinite enumerability is supposedly meaningless, empty of content, and therefore not in itself subject to alteration through contextual change, and idealities such as spoken or written language which are directly animated by a meaning-to-say and are thus immediately affected by context. Derrida associates the dangers of cultural stagnation, paralysis and irresponsibility with the emptiness of programmatic, mechanical, formulaic thinking. This paper endeavors to show that enumerative calculation is not context-independent in itself but is instead immediately infused with alteration, thereby making incoherent Derrida's claim to distinguish between a free and bound ideality. Along with the presumed formal basis of numeric infinitization, Derrida's non-dialectical distinction between forms of mechanical or programmatic thinking (the Same) and truly inventive experience (the absolute Other) loses its justification. In the place of a distinction between bound and free idealities is proposed a distinction between two poles of novelty; the first form of novel experience would be characterized by affectivites of unintelligibility , confusion and vacuity, and the second by affectivities of anticipatory continuity and intimacy.
\end{abstract}


'What Is A Number? Re-Thinking Derrida's

Concept of Infinity'

Joshua Soffer

5701 N.Sheridan Rd.\#29R

Chicago,Il. 60660 (773) 334-0515 


\section{What Is A Number? Re-Thinking Derrida's \\ Concept of Infinity}

Jacques Derrida may be said to be the pre-eminent thinker of movement today. His work demonstrates that no experience can take place outside of the process of its own transformation. If to be self-present is to have an enduring meaning transcending the transformative effect of immediate context, deconstructive dynamics show us that all events of sense and meaning are radically not present to themselves. They are deprived of their claim to be self-persisting forms by virtue of their absolute structural dependence on other events for their very determination. Each singular event of 'writing' (Derrida's term for experience in general) is not what it is except in view of another such singular event, and so on. What appears and passes away as a signifier is not the stand-in for an originating presence, but the repetition of an original undecidability and mobility. The engine of this deconstructive movement is the indissociable play of repetition and alteration dubbed by Derrida as iterability, the repetition which alters the idealization it reproduces..

Derrida writes,"an element functions and signifies, takes on or conveys meaning, only by referring to another past or future element in an economy of traces"(Writing and Difference, p.29). And:

The play of differences supposes, in effect, syntheses and referrals which forbid at any moment, or in any sense, that a simple element be present in and of itself, referring only to itself(p.26).

The fact that all experience is transformative-dissimulative in its essence does not, however, mean that the momentum of change is the same for all situations. It is true that many of Derrida's 
What Is A Number...2

writings on iterability, the dynamics of what he variously calls the mark, trace, hymen and differance, appear to pertain to situations where active and continual contextual change is presupposed. These include speech and reading situations where intentional desire or `meaningto-say' drives the passage of text. But these situations do not express the only typology of iterability. Derrida in fact speaks of forms of iterability ranging from experiences of stiflingly narrow repetitiveness to those of thoroughgoing displacements of fields of cultural programmatics. In numerous writings, Derrida demonstrates how cultural hegemonies dominate via the politics of calculative programmatics of the Same. For instance, within a modern thinking of invention,

...there is a deep continuum of homogeneity, whether we are considering civil or military technoscientific research, or programming, private or governmental, of the sciences and arts. This homogeneity is homogeneity itself, the law of the same, the assimilatory power that neutralizes novelty as much as chance (Psyche:Invention of the Other,p.56).

He also speaks of how such programmatic effects are disrupted from time to time by an intervening, surprising gesture of rupture and displacement:"...one must, at a given moment, stand at the edge of catastrophe or of the risk of loss. Otherwise, one is only applying a surefire program"(Points,p.198). And "A future that would not be monstrous would not be a future; it would already be a predictable, calculable, and programmable tomorrow(Ibid,387)."

The aim of this paper is twofold:

1) To analyze Derrida's account of mathematical idealization, which will be shown to provide the conceptual basis for the myriad sorts of formulaic and unoriginal thinking which Derrida equates 
with moral irresponsibility and cultural paralysis.

2) To question Derrida's claim that mathematical idealization is in its essence context-free, that is, devoid of active intentional animation. If, as this paper will argue, Derrida's concept of numeric infinity as repetition of 'same thing, different time' is incoherent, then Derrida's attempt to tie the ethical thrust of deconstruction to the distinction between forms of mechanical or programmatic thinking (the Same) and truly inventive experience (the absolute Other) loses its justification. If there is no such thing as Infinitude of the Same, the violence of deconstructive transit can no longer know itself as the force of resistance.

Let us begin by examining the relation between mathematical and non-mathematical forms of repetition in Derrida's work. Of the various typologies of iterability Derrida discusses, how is mechanical repetition to be understood in relation to other forms of iterability? A mechanical or mathematical iteration (the 'mathematical' in this paper refers to the primordial act of counting, the symbolization of 'same thing different time') apparently presents a different type of iteration in comparison with that of active intentional experience, where contextual alteration intervenes from instant to instant. Derrida has found it useful to enlist the aid of Husserl in articulating this distinction between mechanical and other varieties of temporalizing experience.

Some readers of Derrida would doubtless suggest that Godel's work on undecidability is a more significant influence on Derrida's philosophy of the mathematical than that of Husserl. Indeed, in Dissemination, Derrida uses Godel's notion of an undecidable proposition in analogy with his own use of the term `undecidability' (which is itself closely linked with `iterability'). 
What Is A Number...4

An undecidable proposition, as Godel demonstrated in 1931, is a proposition which, given a system of axioms governing a multiplicity, is neither an analytical nor deductive consequence of those axioms, nor in contradiction with them, neither true nor false with respect to those axioms(Dissemination,p.219)

Not only does the above quote appear, in a general sense, to capture the dynamic of iterability as a self-dissimulating repetition, but, in 'Origin of Geometry', Derrida notes that Husserl apparently, at one time, adopted a view, corrected by Godel's results, that axiomatic systems could be exhaustively grounded.

However, in `Origin of Geometry' (p.54), Derrida recognizes it is from a more primordial thinking that Husserl approaches the general issue of mathematical objectivity, from which the issue of axiomatic decidability gets its ultimate sense. Relative to this aim, Husserl's pre-Godelian belief in a completely formalizable systemization of axiomatic statements in mathematics was an entanglement in a 'secondary grounding' of mathematical ideality, not to be confused with the fundamental task of phenomenology as the uncovering of the conditions of possibility of objectivity in general. Thus, given the goals of Husserl's analyses, it didn't matter whether he got it right or wrong concerning the limits of the deductive formalizability of axiomatic systems. Derrida writes

Even if Husserl at one time adopted the conception of grounding axiomatics and even proposed it as the ideal for "all `exact' eidetic disciplines"(Ideas I,\$7,p.56), it seems he only considered this to be a SECONDARY grounding. There is no doubt, in any case, that the kinds of primordial evidence he investigates here are for him prior to those of axioms and serves as their ground(Of Grammatology, p.55). 
What Is A Number...5

Derrida is presented, on the one hand, with Husserl's bracketing of Godelian mathematical analysis according to the method of a phenomenological reduction which Derrida finds to be mired in metaphysical presuppositions. On the other hand, Godel's work is guided by his self-declared mathematical Platonism, his belief that humanly-created formal systems are ‘undecidable' only in being incomplete approximations of absolute mathematical truths(footnote 1). Derrida seems to recognize that the phenomenological move, even in its failure to extricate itself from its own version of transcendental idealism, effectively questions the philosophical naivety on which Godel's theory of the object rests.

As Derrida underscores, Husserl refuses "to accept the intelligibility and normativity of this universal structure [of arithmetic] as...an eternal truth created by an infinite reason" (Writing and Difference,p.157). Derrida's notion of undecidability may be properly understood as a deconstruction of the assumptions of mathematical objectivity grounding Godel's thesis. Toward this end, Derrida has been aided in certain ways by phenomenology, even if Derrida has had to leave it behind at a certain point.

Bound vs Free Idealities:

In recent comments, Derrida affirmed his qualified dependence on Husserl concerning this issue:

...I am very interested in and indebted to Husserl's analysis of idealization. One could say that I 'borrow' from him while leaving him at a certain point, and what I borrow from him is the analysis of what he calls `idealization(Arguing with Derrida, p.103).

Specifically, Derrida's groundbreaking reading of `Origin of Geometry' pursues the implications 
What Is A Number...6

of Husserl's transformation of the Kantian thesis that an ideal object of any kind is an ideality in the extent to which it is identically repeatable again and again. As Derrida puts it, "Absolute ideality is the correlate of a possibility of indefinite repetition."(Speech and Phenomena,p.52). Derrida takes up Husserl's interest in this process of idealization, borrowing from Husserl a distinction between bound and free idealities (footnote 2). Derrida deconstructs the Husserlian usage of these terms, transforming them into species of iterability. Spoken and written language, and all other sorts of gestures and markings which intend meaning, exemplify bound idealities. Even as it is designed to be immortal, repeatable as the same apart from any actual occurrences made at some point, the SENSE of a spoken or inscribed utterance, what it means or desires to say, is always tied to the contingencies of empirical circumstance. Derrida explains:

Iterability makes possible idealization-and thus, a certain identity in repetition that is independent of the multiplicity of factual events- while at the same time limiting the idealization it makes possible:broaching and breaching it at once...the possibility of its being repeated another time-breaches, divides, expropriates the "ideal" plenitude or self-presence of intention,...of all adequation between meaning and saying. Iterability alters...leaves us no room but to mean (to say) something that is (already, always, also) other than what we mean (to say) (Limited, Inc,p.61)... It is not necessary to imagine the death of the sender or of the receiver, to put the shopping list in one's pocket, or even to raise the pen above the paper in order to interrupt oneself for a moment. The break intervenes from the moment that there is a mark, at once. It is iterability itself, ..passing between the re- of the repeated and the re- of the repeating, traversing and transforming repetition(p.53).

In the case of a bound ideality, what repeats itself as self-identical returns to itself as 'the same' subtly differently each time; the immediate effects of contextual change ensure that alteration is intrinsic to the repetition of an intentional meaning.

But what if, instead of the spoken repetition of the same word again and again, we use as 
What Is A Number...7

our example an arithmetic counting? A mechanical-mathematical series would exemplify a free ideality. Derrida approvingly summarizes Husserl's belief that

I can manipulate symbols without animating them, in an active and actual manner, with the attention and intention of signification (crisis of mathematical symbolism, according to Husserl)...the emptiness of mathematical meaning does not limit its technical progress (Limited, Inc.,p.11)

Mathematical idealization is unbound (within the strict limits of its own repetition); no contextual effects intervene such as was the case in the attempt to repeat the same word meaningfully. Contextual change implies change in meaning-to-say, and a mathematical ideality can be manipulated without being animated, in an active and actual manner, with the attention and intention of signification'.Such an ideality can be repeated indefinitely without alteration, because its meaning is empty. Derrida expands on this concept of numeration as emptied of intentional meaning in Dissemination:

Now, Numbers, as numbers, have no meaning; they can squarely be said to have no meaning, not even plural meaning (footnote 3). At least, in their movement (writing squared, writing about writing, which covers all four surfaces and is not plurivocal for the simple reason that it does not reside essentially in the vox, in the word), Numbers have no present or signified content. And, a fortiori, no absolute referent. This is why they don't show anything, don't tell anything, don't represent anything, aren't trying to say anything (Dissemination,p.350).

However, while pure idealities are pure, or 'free', in being themselves devoid of specific content and unaffected by any determined context, we must trace their ultimate source to a prior animating intention. After all, there is always a reason for which we calculate. Considerations as when to 
What Is A Number...8

begin a counting for various purposes, when to halt it, via which mathematical schemes or operators to relate series of numbers to each other, these decisions all relate to intentional factors and thus are themselves subject to contextual alteration. Thus, according to Derrida, while the simple possibility of self-identical counting is itself independent of such intercontextual factors, the fact that an in-principle infinite counting is linked to a prior animating intention implies that it be subject to its own death via subsequent mutation of intentional context. The so-called freedom of mathematical infinity is primarily limited, then, not within its own self-same repetition, but with respect to the animating intentionality on which it depends, and which intentionality, or meaningto-say, is in turn bound and divided apriori through its reference to another meaning, and so on.

For Derrida, as for Husserl, the ideality of number, as 'the same again and again' , has its ultimate origin in the structural-genetic basis of the movement of experience itself. Derrida links mathematical repetition to the presence-absence structure of iterability, also referred to as differance, among other names. Husserl, however, grounds the exactitude of calculation in the Absolute living present, as the infinite repetition of the retentional-protentional structure of timeconsciousness.

Derrida notes that according to Husserl,

The `again and again' which hands over exactitude inscribes the advent of mathematics within the prescription of the infinite task. And the latter is grounded...in the movement of primoridal phenomenological temporalization(Origin of Geometry,p.136).

Derrida emphasizes that, in one sense, for both himself and Husserl (and pace Godel) the basis of pure idealization is not "the access to some possibility that is itself ahistoric yet discovered within a history"(Origin of Geometry,p.131).Absolute transcendental subjectivity is "pure active-passive 
What Is A Number...9

temporality,.. pure auto-temporalization of the Living Present"(p.152), the

"discursive...intersubjectivity of Time with itself".

If Derrida is in agreement with Husserl concerning the non-worldly basis of number as a free ideality and its origination in the indeterminate intersubjective movement of temporality, where does Derrida’s account of idealization presume to leave Husserl behind? A key objection stated by Derrida in 'Origin of Geometry' is that Husserl treats the ideality of the structure of intentionality as the preservation or mastery of presence in repetition, what Husserl calls an `Idea in the Kantian sense'. Derrida claims that for Husserl the self-repeating flow of temporality is the repetition of an originating ideal object, the now as pure source-point, (the living present) which stands in front of, is present before the act of repetition (Vor-stellung)(footnote 4). While Husserl thinks the infinite structure of time-consciousness via the regulating telos of an Idea in the Kantian sense, for Derrida the 'now' structure originating experience does not conform to such an Absolute. The structure of temporality has not an Ideal but a quasi-Ideal, or quasi-transcendental character. Rather than a pure unity continually present to itself in its repetition, the NOW is immediately divided within itself as iterability, simultaneously repeating and transforming its sense.

Donn Welton and J. Claude Evans, among others, have disputed Derrida's influential early reading of Husserl. Welton points out that Derrida's analysis of Husserl in Speech and Phenomena was written between 1953 and 54, when only the first six volumes of the Husserliana were available and none of the lecture and manuscript materials from the 1920's were in print. According to Welton, Derrida's determination of Husserl's phenomenology as a new form of Cartesianism does not venture beyond Ideas I, leading Derrida to believe that Husserl's analyses slighted the genetic and historical in favor of a static transcendentalism of purified transparent 
What Is A Number..10

givens (a pure present), thus making alterity inessential to consciousness. Welton argues that Husserl was moving toward a fully intersubjective transcendental philosophy in which indication and expression are not opposed to each other and recollection is contingent rather than apodictic.

There is not space in this article to deal adequately with Derrida's announced differences with Husserl or the controversies surrounding them. It is important to grasp, however, in order to properly situate the argument of this paper concerning Derrida's treatment of idealization, why even the most generous reading of Husserl, such as that of Donn Welton, while perhaps undermining a number of Derrida's early charges against Husserl, fall short of the radicality of Derrida's account. Even if the later Husserl does not consider phenomenology's infinite beginning to be grounded in a regulating telos (an Idea in the Kantian sense), the issue for the purposes of this paper is the extent to which for Husserl the NOW as source point is able to protect itself from the immediacy of contextual influence. Derrida objects to phenomenology's formulation of experience as a perceiving, the appearing of an object before a subject. Husserl's later writing does not escape this formulation of experience as a reciprocally adaptive interaction between subject and object, even if it contextualizes its subjective and objective sides (footnote 5). The percept is still seen as a kind of dividing screen wherein subject-object coupling is a function of perception understood as the receiving of, attending to, turning toward, or being affected by a datum of sense by the 'subject' which receives it. The presencing of an element of experience as a perceiving reifies itself, even if just for a moment, AS itself before it is then EXPOSED to or AFFECTED by an other.

For Derrida, an element of significance as subject or object does not first exist, even for a moment, and then interact. The present is IN ITSELF a `from here to there', an inside and an outside, 
What Is A Number..11

simultaneously an absencing or effacement of a previous element and the presencing of a qualitatively new and different element. The here and now is ITSELF motion, transit. The famous Derridean mantra, 'there is nothing outside the text', refers to a radically temporal understanding of context, a dynamic of inscription more general than the concept of language as symbolic verbal, written or gestural communication. Con-text is not something which events are embedded WITHIN, in the sense of a co-existing spatial frame, background, scheme or body. We are not IN a spatial field, we spatialize-temporalize. In this sense, experience is not em-bodied but debodied(footnote 6).

Appreciating the manner in which Derrida has radicalized the Husserlian conception of context is a necessary prelude to a further step away from Husserl's theory of ideality, a step Derrida does not seem to have been prepared to take but which is already foreshadowed in his notion of iterability. As we have seen, Derrida retains from Husserl's phenomenological investigation of idealization the notion that the exactitude of pure (numeric) ideality is a way of being that is irreducible to the contingency of empirical reality. Derrida agrees with Husserl that "..the meaning of the number...[its "ideal objectivity and normativity"] is precisely independent from any factual consciousness"(Writing and Difference,p.158). It is this belief in the noncontingency of number in its own sphere that we want to challenge. In so doing, we will be putting into question the general principle of iterability which authorizes it. However, matters are not so simple. In point of fact, Derrida's account of iterability imparts an ambivalence to his thinking of numeric infinitization. Specifically, it is not strictly true that for Derrida number in itself is entirely devoid of contingency. Let us see why not.

We have argued that for Derrida a numeric infinity is ultimately finite due to its dependence on the contingency of a prior animating intentionality, but what about status of 
What Is A Number..12

transformation within a counting? We have said that the repetition of a numeric object is in itself not affected by context. This would appear to exempt such a pure ideality from the status of what Derrida calls iterability (a reptition which alters what it reproduces). But in fact numeric counting seems to evince a peculiarly silent kind of supplementarity or dissemination. Derrida explains:

Number is always just beyond or just short of itself, in the "deviation" or "spread" that the machine is designed to read. The plus and the minus, excess and lack, proliferate and condition each other in the supplementary articulation of each with the other. Number, the trace, the frame-each is at once itself and its own excess facing(Dissemination,p.364).

Even in a so-called pure counting, the would-be self-plenitude of the origin is divided by its referential dependence on the previous and next element in the counting. This makes each number in a certain sense unique with respect to the series of numbers to which it is enchained. While it is independent of meaningful, and thus contextual, change (change in intention or meaning-to-say) and thus active alterity, numeration dislocates sense in an empty sort of way, and in this sense number IS an iterable mark.

Let us now form some conclusions concerning the relationship between Derridean infinity and iterability. We have revealed an ambivalence in Derrida's notion of number, preventing its movement from taking on the status of pure non-contingency. Number, along with all other sorts of marks, is essentially constituted-reconstituted by a self-dividing lack and excess. However, it does not seem that such a dislocation operating between-and-as numbers is iterable in the way that an intentional meaning is iterable.. Derrida's descriptions of number are not simply a general explication of iterability itself, but of a peculiar sort of dissemination or mobility, a passage 
What Is A Number..13

through units activated by a particular purpose which number's in-principle infinite extension dislocates but never abandons for another meaningful purpose as long as it simply continues along its self-identical course. A particular counting originates from a specific context of meaning-tosay. One, two , three are always OF something, motivated by an intention which they supplement and decenter.

Compared with the iteration of contextually changing semantic elements, can we really say that a counting frees itself from what is being counted, even if we acknowledge that a counting dislocates by absencing a motivating meaning-to-say from its sense? (7).Can we not then say that the otherness of calculative repetition, in bypassing meaning, is more 'conservative' in comparison with the alterity expressed by contextual transformation, that is, of meaning to say otherwise that what we mean? We couldn't say the numeric mark is dead because it textualizes, but neither can we say that it is animated in the way that a meaningful intention is. It would seem, then, that the empty textuality of numeration helps us to understand the basis of the kind of experience which for Derrida opposes the novelty of a truly inventive event. This feature of counting as empty excesslack would crucially link it to the basis of cultural stagnation as Derrida understands it. That is, the sameness of programmatic, formulaic, mechanically redundant, authoritarian reaches of culture may be grasped via this link to the self-sameness of numeration.

In many of Derrida's writings we see the role of mechanical reproduction in conjunction with the repressive potentiality of experience. Even as continually shifting lines of differential forces deprive even the most totalitarian system from anything more than a provisional stability moment to moment, Derrida frequently speaks of dominant codes, machines, apparatuses, programmatics recycling themselves alone and in combination over a period of time. For instance, in "Psyche:Invention of the Other", he says of cultural attempts to program invention that 
One could say that a certain affective thematics are associated with the region of iterability which Derrida associates with the programmatic, the formulaic, the calculable, the countable.

Affectivities of the too-same, of relative redundancy, monotony, vacuity, stagnation, and paralysis would be associated with the ongoing experience of the `same over and over again'. On the other hand, the dramatic transformation-displacement of these monorhythms and monocodes manifests an affective thematics of the surprising, the shocking, the disturbing and traumatic, strangeness and monstrosity.

The Incoherence of Number:

We must now ask:Can one justifiably link the affective thematics of the 'too-same' with numeration as a whole? And are the sensibilities of surprise and disturbance directly and necessarily to be connected with inventive experience? Let us address the first of these questions now. Our claim is that, with regard to the counting of number, the self-plenitude of the origin is divided not simply because it is supplemented by a next instance of the counting, but because context intervenes (not accidently) in the same way as in any meaningful, intentional experience. In other words, the minimal condition of supplementation-dissemination is not simply that an identical copy supplements, makes up for an essential lack in an origin, but that repetition always 
What Is A Number..15

involves, and is in fact co-determined by, contextual transformation, not accidently but necessarily. An illustration of this idea would be to imagine attempting to count in one's head to 100 by increments of 1 . The task would find one's attention and mood subtly shifting almost immediately, and this should not be construed as simply accidental interferences in a task which could conceivably be kept protected from such distractions. The very sense of what it would mean to be counting, the originating concept of the count, would change instant to instant along with these shifts in mood and attention.

If we then expanded this illustration to apply in a general fashion to any instances and types of concepts of counting, we would have to conclude that there is no such thing as numerical infinitization as it would be understood according to Derrida. Any time and anywhere we experienced the event of a programmatics, a formula, a calculated invention, whether in the actual operation of a device as we experienced it, or in our imagining of a mathematics, we would be experiencing a scene whose temporalizing self-sameness could not be thought of as simply an empty self-dividing supplementation. No general distinction could be made between the iteration of spoken language and that of mechanical counting on the basis of the contribution (or lack) of contextual change.

Derrida continues the philosophical tradition of assessing the meaning of mathematical calculation itself by theorizing the nature of the subjective-objective origins of, and relations to, the self-identical repetition of counting (number as synthetic a priori, number as empirical symbolization, number as pure ideality, number as iterable mark, etc.). But like previous philosophers, Derrida takes as a given the formal constancy of the sense of what counting means WITHIN ITSELF. The present argument is not one concerning the manner in which one should characterize the relation between number and what it refers to. 
What Is A Number..16

That is, the question for us is not what kind of notion of infinity (mathematical versus dynamical, for instance) is to be applied to experience. The issue here is a much more radical one. It is, simply stated, whether the very idea of simple infinity, as `same again and again', has a stable meaning. It is important to see that if the concept `same thing different time' doesn't have the coherence it is assumed to have, then this makes irrelevant from the start the issue of what in the world of homogeneous or heterogeneous empirical, transcendental, or quasi-transcendental objects a numeric repetition is a counting $\mathrm{OF}$.

A so-called additive series re-instates itself each repetition as a subtly different philosophy of addition and thus a subtly different philosophy of the world. What are called procedural, mechanical, formulaic, logic-mathematical forms of repetition are ways of thinking which fail to recognize overtly that any supposedly rote sequencing or regurgitation of a prior scheme drifts slightly askance from its prior sense and intention in each moment of its recurrence. What is it we are doing when we think a concept like `infinity'? The thinking of `same object, different time', the supposed definition of infinity, is just something we say, a contingent utterance which, when we come back to it again the next instant, now says something slightly other. By this reasoning, 'different time' does not really mean different, because if each time in which an infinitely repeating object appeared were really, contextually different from the previous, the meaning of the object would change from one instantiation to the next and thus so would the meaning of infinite. Infinity implies the ability to think the multiple at once. Of course , an element is only itself by being divided from itself and in this sense singularity is intrinsically a double concept. But this singular hinged structuration of traceness is not in itself enough to know a concept like infinity. Infinity must know what it is to count more than one in-between. Before any idea of eternity, or even large magnitude, all notions of infinity begin from the assumption of exact 
What Is A Number..17

duplication. All that is needed in order to allege the transcendence of the finite is to suppose the production of a single identical copy. 'From one to the next to the next'; this, it seems, is a minimal basis of infinity, the common denominator of cumulative reference. It shouldn't matter whether one counts one instance of repeated self-identity or one million. Fundamentally, infinity is the very possibility of `same object, different time'. It is `writing squared', as Derrida put it, the ability to know what groupness in general means, a self-same again and again.

The concept of numeration, of infinitization, would seem to necessitate a comparison between at least three elements of a succession in order to conceive of such a thing as `same object, different time'. For instance, comparing the interval between zero and one, with the interval between one and two, would tell us that this was the exact same interval but two different times. Thus, one would need both the differential relation between a mark and a previous mark (this would constitute the sense of a singular element), and the relation between that previous mark and a mark previous to that one. Most importantly, one would have to be able to think together, at once, both pairs of marks, in order to know that they were the same. In this way we could compare singular elements in order to judge them the same. Without the ability to think groupness at once, simultaneously, experience must be recognized as always a particular `from this to that' with no room for an `all of these' or `more than these'. The numbers 8 or 2 are recognized in their immediate relation to what precedes them or follows them in a thinking, but not as members of what could be conceived as a self-same series whose empty meaning presumably knows itself, is empirically unchangeable. The inability to know 8 or 2 as belonging to ongoing self-sameness deprives them of their claimed categorical distinction, as number, from other types of marks or words.

If a supposed counting from one to ten is at the same time a repetition of supplement of 
What Is A Number..18

degree and of kind then it is no longer (and never was) within numerical calculus, presumed as a self-evident exercise. As soon as a thinking of moreness as pure difference of degree is destabilized, number is seen as having already transgressed the authority of self-identical accumulation before it can enumerate. Calculation reaches the limit of its totalization before it can simply count. As soon as there is a counting of one, we are thrown back into the origin, differently, so that there is never a counting past one (as bifurcated singular). The one, the first and only one, is also the last one as doubled origin and its repetition. The instant of experience returns to the same magnitude differently, which is other than the supposed simple coherence of number.

Derrida's acceptance of such a thing as numeration or infinity depends on his assumption of an irreducible thickness or stasis within the structure of a trace (element) of meaning. There is an indissociable relation between his conceptualization of infinity and his concept of desire. The conservatism of cultural stagnation, linked as it is to the alleged emptiness of mechanization, formalization, numeration, has its ultimate justification in that within the trace which functions as conservatism itself.. The singular trace thinks it knows what infinity is, and so in a sense the singular is already plural; infinity is presupposed by a singular event before anything is actually counted. Derridean singularity would be something like an infinite line (fold, margin, surface, force, frame, border). This is not to suggest that one could fit any particular geometry to a trace. The presupposed thickness of an element of meaning, an infinite numeric thickness of presencing alongside an infinite numeric thickness of absencing, makes the Derridean mark or trace blind to a variated movement of gentle, insubstantial affective texture which immediately overruns the concept of infinitization. The attempt to count self-identically unknowingly succumbs to a destabilization before it can think a single instance of its counting. The Derridean notion of infinity as something more than just a contingent intentional-semantic sense depends on the so- 
What Is A Number..19

called repetition of a presence which never changes via an absencing which only occurs once; his infinity is just a contingent placemark with no real activity. 'Same thing, different time' functions always as the same different time and thus as no difference at all, that is, no experience at all, beyond a first declaration of 'this infinite counting'. The supposed determinativeness of the process of infinitization reveals itself as phantasm repressing a more intimate, unformidable series of effects. To recognize that it is always a contextually different concept of number which returns to itself each time is to understand why there is no such thing as number in the sense of an infinitization of self-same intervals.

In asserting that the concept of infinity, as repetition of `same thing, different time' is incoherent, we are not privileging finitude, but suggesting that the finitude/infinitude couplet assumes too much polarizing substantiality for an element of meaning. The movement of experience can only recognize multiplicity in the form of the singular relation from this to that, from a here to a there, in the in-between constituting adjacent elements of meaning. As soon as one moves from this singular differential to the relation to a new element the count begins anew. This does not mean that we cannot think such terms as groupness, plurality and even infinity, but that what we are doing when we think these terms is to name contingent and unique figures within a contextually changing movement whose vicissitudes of momentum exceed any prefabricated notion of what counting is.

We must be sharply attuned to affectivities in order to see this richness. A supposed numeration is nothing but its affectivities. Wherever in culture Derrida would see simply the effects of the black hole of infinite mechanism, we see an intricate undulation of textured sensesaffectivities. The acuteness of Derrida's blindness in this regard is exemplified by his failure to see that it is via the very experiences of predictability, anticipation and familiarity he associates with 
What Is A Number..20

stagnation that novelty may be most intensely available to us. By the same token, affects of shock, surprise, strangeness, monstrosity, which Derrida directly associates with the experience of the absolute other, can be seen in a certain way as the essence of stagnation itself.

Note these comments of Derrida:

...a philosophical discourse that would not be provoked or interrupted by the violence of an appeal from the other, from an experience that cannot be dominated, would not be a very questioning, very interesting philosophical discourse(Points,p.381). A future that would not be monstrous would not be a future; it would already be a predictable, calculable, and programmable tomorrow. All experience open to the future is prepared or prepares itself to welcome the monstrous arrivant, to welcome it, that is, to accord hospitality to that which is absolutely foreign or strange, but also, one must add, to try to domesticate it (p.387)...All of history has shown that each time an event has been produced, for example in philosophy or in poetry, it took the form of the unacceptable, or even of the intolerable, of the incomprehensible, that is, of a certain monstrosity. When it is alive in some way, when it is not sclerotically enclosed in its mechanics, the philosophical discourse goes from jolt to jolt, from traumatism to traumatism(p.381).

Here we see Derrida associating the thinking of numeric self-sameness with affectivities of emptiness, meaninglessness, paralysis, boredom, immobility, complacency. Meanwhile, the experience of an absolute other is heralded by affects of shock, surprise, trauma, strangeness, monstrosity, risk. Derrida's linking of redundancy with infinitization leads him to oppose the selfenclosed mechanics of the same to the displacement of a mechanics. We saw that for Derrida socalled wearingly redundant experience is experience which clings too tightly to an (non-original) originating conceptual frame or code. But we have insisted that the concept of numeric sameness motivating this thinking is necessarily incoherent, painting a whole vicinity of varied affective textures with one brush. We need to extricate affectivities of stagnation from the concept of Sameness (the possible), which doesn't tell us anything. In like manner, we need to wean senses of 
What Is A Number..21

traumatic, disturbing displacement from their dependence on an incoherent concept of Otherness (the impossible).

If there is only ever experience of contextual transformation, the would-be distinction between mechanical repetition and inventive alterity can be re-thought as a distinction between two types or momenta of novelty. Experiences of unintelligibility and meaninglessness represent a type of movement characterized by apparent emptiness and paralysis. Boredom, monotony, weariness and exhaustion connected with redundant experience would be, paradoxically, of the same species as the shock and trauma of dramatic otherness. As counterintuitive as it may seem, repetition of experience could only be perceived as redundant to the extent that such monotonous experience disturbs us by its resistance to intimate readability. Boredom and monotony are symptoms not of the too-predictable, but of a previously mobile, fluidly self-transformative engagement beginning to become confused, and thus seemingly barren of novelty.

So-called wearingly redundant or vacuous experience evinces the same pathology as the shocking and disturbing because these two types of events are variants of the same condition; an ongoing dearth of coherence or comprehensibility. The confusion, incoherence and mourning at the heart of experiences of monotony and exhaustion as well as shock and surprise manifest a referential-differential chain of barely registerable elements, a strange territory barren of recognizable landmarks. The 'too same' and the 'too other' are forms of the same experience; the terrifying mobility of the near-senseless, the impoverishment, moment to moment, of the meaning of each new event. It is AS IF the rate of repetition of novelty has been decelerated during experiences of crisis. We know that we are no longer what we were in such states, but we cannot fathom who or what we, and our world, are now; we are gripped by a fog of inarticulation. While still representing transit, such a destitution or breakdown of sense seems like an ongoing 
What Is A Number..22

redundancy, a death of sense.

If the affectivities of disturbance and incomprehensibility Derrida associates with significant novelty are in fact symptoms of apparent stagnation and paralysis (but not the alleged infinitude of the Same), which sorts of affects are indications of effective novelty? The unknown, the absolutely novel, may be most intensely available to us to the degree that we anticipate the unanticipatable, which is only to say that a certain intimacy, continuity and gentleness pervade our most effective movement through repeated novelty. It is not affectivities of the shocking, the surprising or the strange which inaugurate our escape from the monotony and complacency of perceived authoritarian, vacuous repetition, since the latter are precisely species of the former. It is affectivities of joyful, interested engagement which express an acceleratively mobile engagement with otherness. The most stimulatingly fresh pathways imaginable are direct measures not of the confused incomprehension of disturbance but of the intimacy of familiar anticipation. Activities associated with programmatic and formulaic calculation cannot exclusively be correlated with either of the above two types of movement. Whether such an activity is deemed an impoverishment or an acceleration of novelty depends on the particular affectivities associated with that activity determining its shifting purpose and sense, and not on the presumed self-evident fact of the experience of the so-called calculative order itself.

In coming back to itself moment to moment as the familiar, the anticipatable, the predictable, desire may continue to reaffirm its preference even as, or precisely because, the very basis of that objective is subtly re-invented in each instantiation of it. Since we are in (we exist as) transit before we could ever choose to motivate ourselves, the variability of motive resides in the relative perceived continuity of the movement of our experience, event to event. The option we face is between a more or less (non-countably) accelerated experience of movement through what 
What Is A Number..23

is always, moment to moment, utterly fresh experiential terrain. Shocking, threatening and even boring events manifest a seemingly paralyzed trudge through the chaos and confusion of the unintelligible, while interesting and enjoyable situations express a (non-countably) denser rhythm of change. We always and only find ourselves preferring, and preferring more and more intensely (differently moment to moment), more and more richness (density, continuity) of novelty. Desire is always the desire to make sense, and to make sense is always to make new sense. Narcissism is not the love of redundancy but the love of novelty in its guise as presence. The impetus of narcissism is toward otherness itself in its most accelerative manifestations.

\section{A Politics of Intimacy:}

The deconstructive play of Same and Other involves an irreducible violence and polarization. Concealing the vicissitudes of an intimate experiential movement, it always comes too late, noticing and endorsing a wrenching extrication that it reifies as a necessarily traumatic disruption-displacement. A radicalized thinking of differance must place in question a comment of Derrida's like the following: "When it is alive in some way, when it is not sclerotically enclosed in its mechanics, the philosophical discourse goes from jolt to jolt, from traumatism to traumatism"(Points,p.381)(8). As a most insubstantial play, the pivot of sense does not have the power to jolt. This peculiarly gentle intimacy of transit must be seen as underlying not just experiences of joy and contentment but also those events characterized by confusion and suffering.

Danger, risk and terror are adjectives Derrida comes back to time and time again to illustrate what it is like to break from the vacuousness of mechanical self-sameness, the merely possible. But these terms of violence are too lugubrious to do justice to a transit which can no 
What Is A Number..24

longer be understood as resistance to the Same. If there is no such thing as Infinitude of the Same, or the 'possible', then the violence of deconstructive transit can no longer know itself as the force of resistance. Unavailable to the overt articulations of deconstruction is a peculiarly gentle notion of alteration whose functioning, throughout experiences of joy and suffering, is that of sense's return to itself differently-but-integrally, a carrying-forward which re-invents its direction and sense every moment without rending the intimate fabric of its anticipative continuity. It is important to understand that this conception of novelty as assimilative is not at all what Derrida has in mind when he thinks of the anticipatable, the predictable, the familiar, the possible as an arrest of inventive experience. We agree with Derrida that the intimacy of experience is not effectively measured by its presumed sustained reproduction of an origin.

The radical intimacy we are speaking of, referentially linking one moment of experience to the next, is driven not by a deductive mechanics, but by the utter insubstantiality of both the presencing and absencing poles of each absolutely new element of experience. The always novel altering-repetition of experience has not the power to disturb to the same extent as it lacks, each time, the thickness of Derridean presencing.

It is important to question the necessity for a language requiring the forceful or resistant intervening in supposedly entrenched regions of power when a radical, subliminal weave of continuity-novelty already functions from within those communities to keep experience mobile. Even within the most supposedly foundational, fundamentalist community of belief or institution of power, each singular individual, in reaffirming the so-called norms and programmatics of that community, is doing this differently each moment of experience, finding their own intention subtly exceeding itself from within in the instant of its affirmation. Given this intricately, constantly mobile relationship of individuals to a particular cultural institution, and more importantly, to 
What Is A Number..25

themselves moment to moment, one could not in fact locate any aspect of institutional practice, regardless of (and in fact because of) how rigidly rule governed it intends its programmatics to be, which would not avail itself to continual, if subtle, re-formulation (or, more precisely, re-sensing) for each individual each instant.

A foundational choice, rule, mechanics, is always, for every individual and at every moment, reaffirmed differently, as the transit or carrying forward of something that in each iteration is other than a mechanics. Programmatics, mechanics, institutional repetitions and norms never actually mean anything except as terms of language favored by individuals who nevertheless, in their use of these terms, immediately and unknowingly multiply the terms' senses. This ongoing transformation of the sense of a norm, standard or rule in its moment to moment usage may simultaneously ensure its continuity and reintroduce it to itself as a new philosophy of itself. This stability, when it is not thrown into crisis, is the reliability of innovation, not the stricture of redundancy. In this light, we would not follow Derrida's observation that in attempting to oppose oneself dialectically to a point of view, this "reversal reproduces and confirms through inversion what it has struggled against"(Points,p.84). Derrida believes one remains wedded to that system of thought which one wishes to overcome, dialectically or otherwise, 'once and for all'. But, examined more closely, it becomes clear that one's opposition to a given way of thinking expresses a transformative shift in one's relation to that which one remains related-through-protest. The dialectician doesn't simply `reproduce and confirm' what he struggles against, but reproduces and confirms differently.

The totalizing schemes of the Hegelian dialectician, or any applied programmatics, evince continuous alteration within themselves instant to instant, not in spite of, but in accord with their impetus, which we have identified as a striving for the effective continuity of the new. Desire IS 
What Is A Number..26

desire for intelligible novelty. The fundamental reality of an allegedly formulaic thinking is not at all that it expresses a less than meaningful otherness each moment of its repetition, but that our experiencing of such a series (and there is no apparatus of supposed duplication, no 'physical' machine, apart from our contingent experience of it) is open to an indefinite range of affectivities of momentum, from the confused paralysis of unintelligibility to the exhilaration of dense transformative movement. Which particular range of momenta of experience reveals itself within what would monolithically be called formulaic or mechanical thinking is determinable via an intricately subtle examination of its affective or sense modulations.

Whether one embraces what would be called repression, a status quo or revolution, one finds oneself preferring the most permeable navigation through experience that appears to be available. The most restrictive conservatism (not regardless of what a so-called dogmatist says, but inherent in what he means) wishes, precisely via the imposition of rules, conventions and contracts, to protect the intimacy of transitivity from the stultifying fog of disorientation as he sees it. Belief in pure conceptual repetition, and even the brief stasis of scheme, is seen by those who subscribe to such notions in relation to less mobile possibilities. It is not that they perceive at some unconscious level and then reject a fresh thinking, an other heading, but that such an alternative does not yet exist for them. What is attacked or opposed, often violently, is not novelty-alterity but the perceived threat of a return to a discredited, stultifying past. The totalitarian dangers Derrida associates with what he sees as too restrictive social programmatics are not the consequence of the stabilizing (but not absolute) hold of a thematics on experience, but, on the contrary, of a disintegration of that thematics.

The enormous variety of thinking depending on myriad sorts and degrees of totalitarianism of the concept, on programmatic mechanisms, on the self-presence of the intending subject, is in 
What Is A Number. .27

each case an internally decentering thinking which may in this or that circumstance be characterized by a relative interruption of experienced momentum, but such experience of confusion and inarticulation must be determined from within that cultural scene via the internal experience of crisis in comprehension, rather than judged in relation to its supposed enslavement to programmatics of the Same. The possibility of altering an ethico-political stratum proceeds, individual by individual, as either participation in overcoming an already perceived crisis, or else in embracing and furthering the effective movement of individuals. There is no room for an intervention from an outside which supposes itself to confront or resist a hegemonic mechanics. But is it fair to characterize deconstructive intervention this way? Derrida writes:

The movements of deconstruction do not destroy structures from the outside. They are not possible and effective, nor can they take accurate aim, except by inhabiting those structures. Inhabiting them in a certain way, because one always inhabits and all the more when one does not suspect it. Operating necessarily from the inside, borrowing all the strategic and economic resources of subversion from the old structure...(Of Grammatology,p.24).

Is deconstruction really operating from the inside when it misses the affective, meaningful variability hidden within terms like `programmatics'? Deconstruction remains in a certain state of estrangement and incomprehension in relation to itself and others precisely when it believes it is effectively inhabiting the other's thinking. A radical intimacy and empathy is unavailable to such a thinking when it determines the basis of experience as an irreducibly violent, subversive and traumatic transit between events. Deconstruction, having no choice but to plunge the other into a chaotic transformation, stunts the fluidity of the other's self-transformative efforts. Rather than coaxing the other into crisis by 'resisting' and subverting the rhythm of their supposedly intransigent, complacent, iresponsible thematics, we may instead recognize a subliminal mobility 
What Is A Number..28

in the other's motives and plans unacknowledged by deconstructive thinking. Rather than forcing the other to another heading, we may more gently move with and from their already subliminally self-transforming heading. 


\section{Footnotes}

1.)See Roger Penrose's The Emperor's New Mind:Concerning Computers, Minds and the Laws of Physics, p,113.

2.) See "Origin of Geometry", pp.72-74

3.) These quotations are extracted from `The Supernumerary' chapter of Dissemination, in which Derrida's thought intertwines itself with a work (among others) from Phillipe Sollers called 'Numbers'. One must pay particular attention to Derrida's usage of the word `numbers' here, since Sollars' text is not generally devoted to a literal analysis of numeration. When Derrida refers directly to Sollers' text, he italicizes the word 'numbers' and capitalizes its first letter. When Derrida uses the word `number', `numbers' or related derivations without italics, he is apparently speaking of a general concept of number. The quote this reference points to mentions `numbers' both with and without italics.

4.) In Speech and Phenomena, Derrida relates Husserl's formalistic account of infinity to his theory of language. Derrida argues that Husserl's distinction between the indicating and expressing function of language reflects the belief that the pure or ideal expressive function of language can be more or less protected from the altering effect of language's role as indication. This in turn implies that an originating sense or meaning is directly transmissible and reproducible 
What Is A Number..30

across time as self-identical, without being OF NECESSITY contaminated by impurities.

5.)Amid the clamor of voices defending phenomenology against deconstruction, one can locate writers such as Bernard Stiegler and Richard Bearsworth treating deconstruction as if it were itself a phenomenological anthropology. See Bennington's critical essay `Emergencies', in Interrupting Derrida $(2000)$.

6.)Don Welton, like Husserl, clings to the idea of language as a conceptual schematism.. Welton understands language in a formal sense in which words are interpretive devices defined within semantic fields in a kind of Saussurian structuralism of relations of similarity and contrast between signs, prototypes, abstract categories. This allows him to distinguish between the supposedly derived nature of language and the originality of perception. Welton says "We have a type of involvement with things that does not require the mediation of language; things have a sense or significance that is not reducible to a function of meaning...the notion of background carries us beyond the limits of language"(The Other Husserl,p.392).

7.)Derrida claims the repetition of a prior animating intention through mathematical idealization does not preserve but interrupts its sense. The would-be preservation of an intended meaning is expropriated "by the mark of numbers, whose nonphonetic operation, which suspends the voice, dislocates self-proximity, a living presence that would hear itself represented by speech.(Dissemination,p.331)." 


\section{Works Cited}

Bennington, Geoffrey:Interrupting Derrida..London:Routledge(2000).

Derrida, Jacques:Speech and Phenomena and Other Essays on Husserl's Theory of

Signs.Trans.D.B. Allison. Evanston:Northwestern University Press(1973).

Derrida, Jacques:Of Grammatology.Trans.Gayatri Chakravorty Spivak.Baltimore:Johns Hopkins University Press(1974).

Derrida, Jacques:Ellipsis. In Writing and Difference. Trans.Alan Bass.Chicago:University of Chicago Press(1978).

Derrida, Jacques:Edmund Husserl's "Origin of Geometry": An Introduction. Trans.J.P. Leavey, Jr.Stony Brook:Nicholas Hays(1978).

Derrida, Jacques:Dissemination.Trans.Barbara Johnson. Chicago:University of Chicago Press(1981).

Derrida, Jacques:Limited Inc.Trans.Samuel Weber.Evanston:Northwestern University 
Press(1988).

Derrida, Jacques:Psyche:Invention of the Other.Trans.Catherine Porter and Phillip Lewis. In Reading de Man Reading, Wlad Godzich and Lindsay Waters, Eds.Minneapolis:University of Mineapolis Press(1989).

Derrida, Jacques:The Other Heading:Reflections on Today's Europe. Trans.Pascale-Ane Brault and Michael Nass.BLoomington:Indiana University Press(1992).

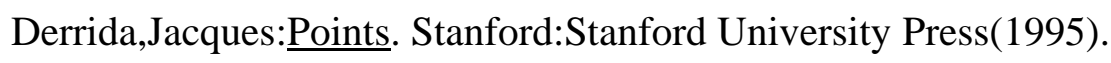

Derrida, Jacques:"Of the Humanities and Philosophical Disciplines, Roundtable Discussion", Surfaces, Vol.VI.108(v.1.0A-16/08/1996).

Derrida, Jacques: Death and Meaning:Derrida's Response to Baldwin, In Arguing with Derrida,S. Glendinning Ed.London:Blackwell(2001).

Penrose, Roger:The Emperor's New Mind:Concerning Computers, Minds and the Laws of Physics.New York:Penguin Press(1991).

Welton, Don:The Other Husserl: The Horizons of Transcendental Phenomenology.Bloomington:Indiana University Press(2000). 

